\title{
Activation of Silicon- and Tin-Carbon Bonds. 1,1- Carboboration of Alkynylsilanes and -stannanes
}

\author{
By Bernd Wrackmeyer
}

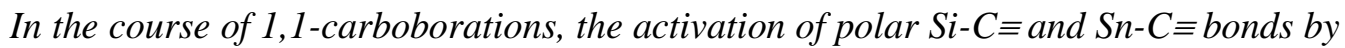
electrophilic triorganoboranes, $B R_{3}\left(R=\right.$ alkyl. aryl, $\left.C_{6} F_{5}\right)$ is used to build new $C-C$ bonds. Expectedly, alkynyltin compounds were found to be much more reactive than the corresponding silanes. Monoalkynyl derivatives lead to organometallic-substituted alkenes, quantitatively and stereoselectively in most cases. Dialkynylsilanes $R_{2}^{2} \mathrm{Si}\left(C \equiv C-R^{l}\right)_{2}\left(R^{l}=\right.$ alkyl, aryl, silyl; $R^{2}=H$, alkyl, allyl, vinyl, aryl, $\left.C l\right)$ react with $B R_{3}$ via twofold 1,1-carboboration by selective formation of siloles. In the case of dialkynylstannanes $R_{2}^{2} \operatorname{Sn}\left(C \equiv C-R^{l}\right)_{2},\left(R^{l}=\right.$ alkyl, aryl, silyl; $R^{2}=$ alkyl, benzyl, aryl, amino) the analogous reactions lead mainly to stannoles or alternatively to 1 -stanna4-bora-cyclohexa-2,5-diene derivatives, depending in a complex way on substitutents $R$ at boron and $R^{l}$ at the $C \equiv C$ bond. The high reactivity of the $S n-C \equiv$ bonds allows the reactions to be conducted under mild conditions enabling the isolation and structural characterisation of intermediates. These possess a zwitterionic structure, in which typically an almost trigonal planar surrounded tin atom is side-on coordinated to the $C \equiv C$ bond of an alknylborate unit. Extending these reaction principles to tetraalkynylsilanes $\mathrm{Si}\left(C \equiv C-R^{1}\right)_{4}$, one obtains 1,1'-spirobisiloles via fourfold 1,1organoboration. Similarly, 1,1'-spirobistannoles can be prepared starting from some tetraalkynylstannanes $\operatorname{Sn}\left(C \equiv C-R^{I}\right)_{4}\left(R^{I}={ }^{i} \mathrm{Pr},{ }^{t} \mathrm{Bu}\right.$, $\left.\mathrm{SiMe}_{3}\right)$.

Keywords: Alkynes, Boranes, Carboboration, DFT calculations, Heterocycles, Hydroboration, Lewis acids, NMR spectroscopy, Silanes, Silole, Stannanes, Stannole, $X$-ray analysis

\section{Introduction}

The trigonal-planar surrounded boron atom in boranes is an electrophilic centre, and therefore, major aspects of the chemistry of boranes deal with Lewis-acid-base interactions (Yamamoto, 1999), by which the electron deficiency of the boron atom is compensated to some extent. The Lewis-acid strength of boranes depends on the electronegativity of the substituents (e.g. in boron halides), their ability to become engaged in (pp) $\pi$ interactions (e.g. with the lone pair of electrons at nitrogen in aminoboranes), and also on steric requirements (e.g. bulky organyl groups $\mathrm{R}$ in $\mathrm{BR}_{3}$ ). Thus, for a given Lewisbase, one encounters a continuum of strong or weak interactions with boranes. Focusing on triorganoboranes $\mathrm{BR}_{3}$, many of these boranes can be classified as "soft" electrophiles, except of the perfluorinated species, such as $\mathrm{B}\left(\mathrm{C}_{6} \mathrm{~F}_{5}\right)_{3}$. (Piers Chivers, 1997; Kehr and Erker, 2012, Hansmann et al., 2014).

\footnotetext{
${ }^{*}$ Professor, University of Bayreuth, Germany.
} 
It is well known that apparently weak interactions may be the origin of unexpected reactivity. In the context with boranes, frustrated Lewis-pairs (FLP chemistry) are particularly noteworthy (Stephan, 2008; Stephan, 2009; Stephan and Erker, 2010; Stephan and Erker, 2014; Kehr et al., 2013). Owing to the polarity of Si-C or $\mathrm{Sn}-\mathrm{C}$ bonds in organosilanes or -stannanes, enhanced in the case of alkynyl carbon atoms in alkynylsilanes and -stannanes, the carbon atom next to Si or Sn can be regarded as a weakly nucleophilic centre. This centre is ready to interact with the electron deficient boron in $\mathrm{BR}_{3}$, either intermolecularly or intra-molecularly (Wrackmeyer, 1995a; Wrackmeyer, 2006) (Figure 1).

Figure 1. Activation of polar metal-carbon bonds by electrophilic triorganoboranes

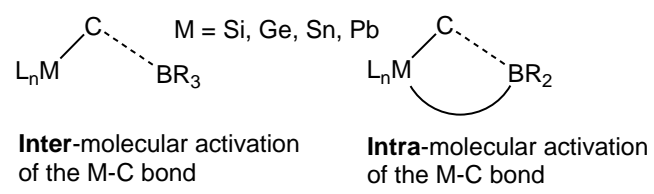

Clearly, activation of the $\mathrm{Si}-\mathrm{C}$ bond will be less favourable than that of the $\mathrm{Sn}-\mathrm{C}$ bond, and the inter-molecular process is energetically more demanding when compared with the intra-molecular one. The $\mathrm{B}{ }^{*} \mathrm{C}$ interactions may either be too weak for any further reaction to take place or the system will find another energetical minimum, which usually involves reversible or irreversible rearrangement(s).

A large variety of alkynylsilanes and -stannanes is readily available following literature procedures (Davidsohn and Henry, 1967; Brandsma, 1988), and the same is true for triorganoboranes (Brown, 1975; Köster, 1984; Pelter, 1988). Here, the principles of 1,1-carboboration will be shown for monoalkynyl metal compounds. Applications and the mechanism of 1,1carboboration of dialkynyl derivatives are demonstrated, and this is extended to Si- and Sn-tetralkynyl derivatives. Finally, the combination of well known 1,2hydroboration (Brown, 1975; Matteson, 1995) and novel 1,1-carboboration are introduced (Wrackmeyer et al., 2003a; Wrackmeyer et al., 2005; Wrackmeyer et al., 2008b; Kehr and Erker, 2012; Khan et al., 2008; Khan et al., 2009b; Khan et al., 2014; Khan and Wrackmeyer, 2014), offering most attractive routes to new silaheterocycles.

\section{Results and Discussion}

\section{1,1-Organoboration of Monoalkynylsilanes and -stannaes}

Scheme 1 shows the principles of 1,1-organoboration reactions of alkynylmetal compounds. The weak interaction in the beginning becomes stronger, leads to cleavage of the $\mathrm{M}-\mathrm{C} \equiv$ bond, formation of a zwitterionic intermediate, followed by shift of one organyl group from boron to carbon. The metal fragment migrates from one alknyl carbon atom to the other, and finally, the metal fragment and the boryl group end up in cis positions at the $\mathrm{C}=\mathrm{C}$ 
bond. In most cases this is a stereo selective and quantitative reaction (Wrackmeyer, 1995a; Wrackmeyer, 2006). In the case of $M=S n$, the reactions are complete after warming the reaction mixtures to room temperature. By contrast, for $\mathrm{M}=\mathrm{Si}$, it is necessary to heat the mixtures at $100-120{ }^{\circ} \mathrm{C}$ for several hours or even days (Wrackmeyer et al., 2008a).

Scheme 1. Principles of 1,1-organoboration of monoalkynylmetal compounds, shown for triethylborane BEt $t_{3}$; quantitative and stereoselective (in most cases) synthesis of organometallic-substituted alkenes

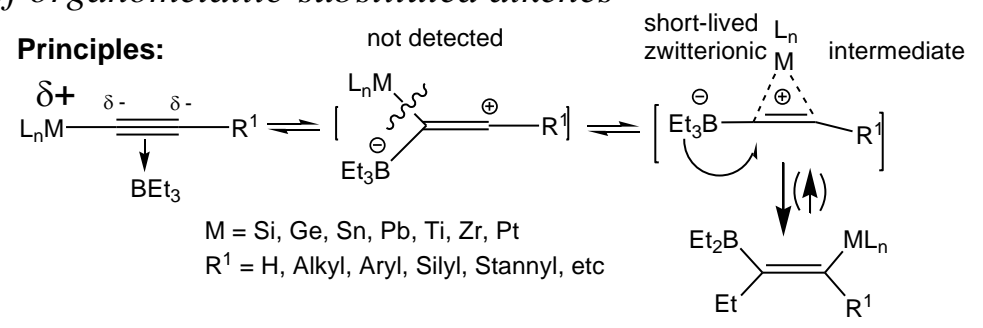

These organometallic-substituted alkenes are attractive for numerous transformations, not discussed here. In Scheme 2, the various reactive sites are indicated by arrows, and some of the relevant chemistry has already been studied (Wrackmeyer, 1987; Köster et al., 1989; Wrackmeyer and Wagner, 1989; Wrackmeyer and Horchler, 1990; Wrackmeyer and Wagner, 1991; Wrackmeyer et al., 1993a).

Scheme 2. Reactive sites (indicated by arrows) of an alkenylstannane, prepared by quantitative and stereoselective 1,1-ethylboration of alkynyl(trimethyl)stannanes (see Scheme 1 for $R^{1}$ )

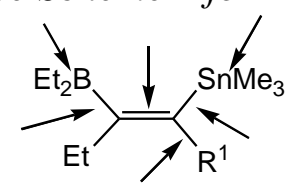

The reversibility of 1,1-organoboration, indicated in Scheme 1, becomes readily apparent by warming the alkene shown in Scheme $2\left(\mathrm{R}^{1}=\mathrm{SnMe}_{3}\right)$ slightly above room temperature. Triethylborane is eliminated, and the bis (trimethylstannyl)ethyne form reacts immediately with the alkene by 1,1 carboboration, transferring the alkenyl group (1,1-vinylboration). This leads to a short-lived buta-1,3-diene which gives quantitatively the allene by irreversible allylic rearrangement (Scheme 3). Such an unprecedented straightforward allene synthesis can be carried out with many boryl substituted alkenes and bis(trimethylstannyl)ethyne (Wrackmeyer and Zentgraf, 1978; Wrackmeyer and Bihlmayer, 1981; Wrackmeyer et al., 1996a; Wrackmeyer et al., 2003b), monitored conveniently by IR and ${ }^{19}$ Sn NMR spectroscopy of reaction solutions. 
Scheme 3. Reversibility of 1,1-organoboration, formation of a 1,3-butadiene and rearrangement into an allene

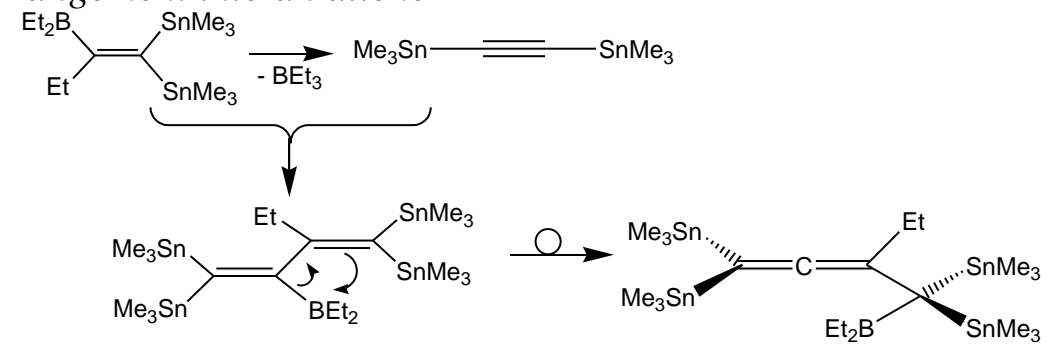

1,1-Organoboration of Dialkynylsilanes, -stannanes: Siloles, Stannoles and 1Stanna-4-bora-cyclohexa-2,5-dienes

Dialkynylsilanes react slowly with triethylborane after several hours at 100 ${ }^{\circ} \mathrm{C}$ to give siloles selectively (Köster et al., 1993a; Wrackmeyer et al., 1993c), Using the much stronger Lewis acid, $\mathrm{B}\left(\mathrm{C}_{6} \mathrm{~F}_{5}\right)_{3}$, the reaction proceeds under milder conditions, also affording siloles (Dierker et al., 2009; Ugolotti et al., 2010) (Scheme 4). Since intermediates were not detected, the mechanism was just assumed to be similar as for monoalkynylmetal compounds, now involving two steps of 1,1-carboboration. The siloles with $\mathrm{R}^{1}=\mathrm{H}$ (Scheme 4) are not stable at ambient temperature. They undergo fast [4+2] cycloadditions to give 7-silanorbornadiene and 7-silanorbornene derivatives (Wrackmeyer and Süß, 2002). In any case, this is a highly convenient silole synthesis (Wrackmeyer, 2006, Wrackmeyer and Tok, 2008; Khan et al., 2009a; Khan et al., 2009b; Khan et al., 2009c).

Scheme 4. Twofold 1,1-organoboration of dialkynylsilanes affords selectively siloles
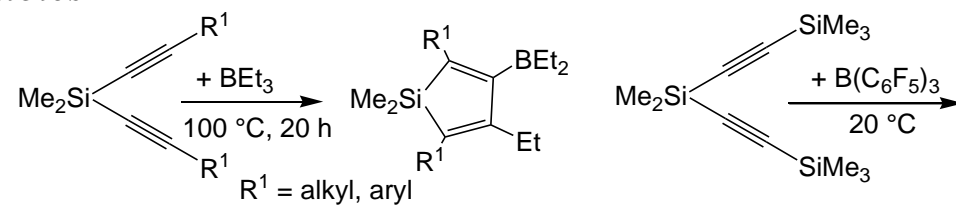

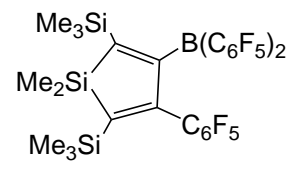

Dialkynylstannanes react with all triorganoboranes already below room temperature. It was found that diethynylstannanes always give stannoles, when treated with trialkylboranes. This was observed in the first studies of this type (Scheme 5) (Killian and Wrackmeyer, 1977) and also later on, using 9-alykl-9borabicyclo[3.3.1]nonanes (Wrackmeyer et al., 1996b) and various other organyl groups at tin (Wrackmeyer et al., 2013). The unambiguous identification of the stannole structure in solution is based on NMR spectroscopy, in particular on ${ }^{13} \mathrm{C}$ NMR (Figure 2). The diene system gives rise to four different ${ }^{13} \mathrm{C}$ NMR signals, one broad (C-3) owing to partially relaxed scalar ${ }^{13} \mathrm{C}-{ }^{11} \mathrm{~B}$ spin-spin coupling $\left({ }^{11} \mathrm{~B}\right.$ : $\left.\mathrm{I}=3 / 2\right)$, and three sharp, accompanied by satellites due to one-bond (C-2, C-5) and two-bond (C-4) ${ }^{117 / 119} \mathrm{Sn}-{ }^{13} \mathrm{C}$ spinspin coupling. 


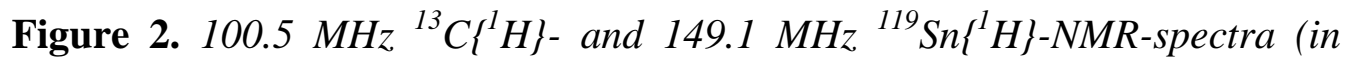
$\mathrm{CDCl}_{3}$ at $296 \mathrm{~K}$ ) of a stannole (Wrackmeyer et al., 2013). Coupling constants ${ }^{n} \mathrm{~J}\left({ }^{117 / 119} \mathrm{Sn},{ }^{13} \mathrm{C}\right)$ in $\mathrm{Hz}$ are given in brackets, marked by asterisks

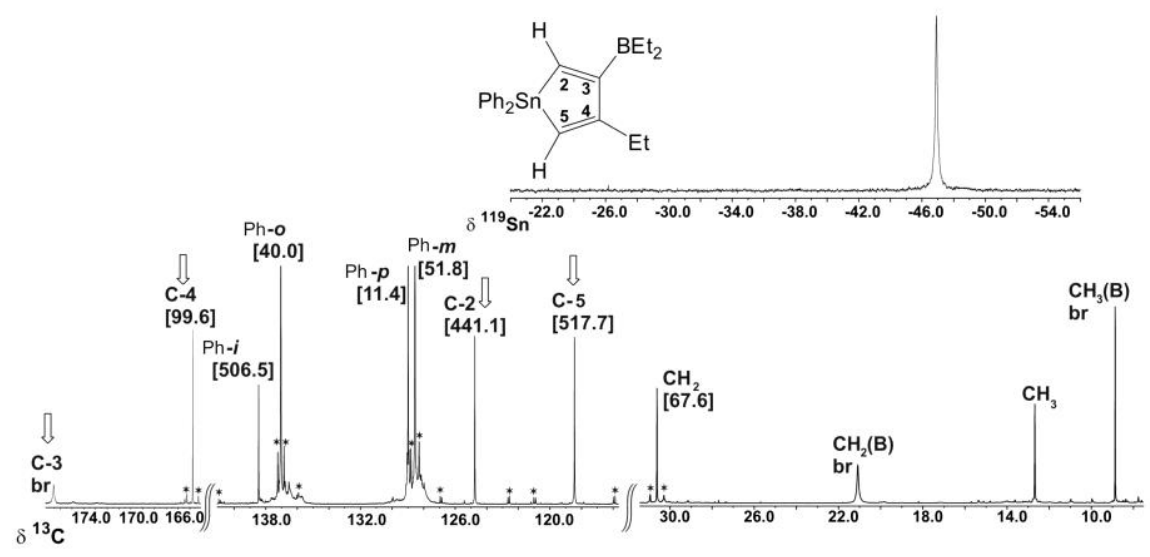

Interestingly, diethynylstannanes react with the strongly electrophilic $\mathrm{B}\left(\mathrm{C}_{6} \mathrm{~F}_{5}\right)_{3}$ to afford exclusively the 1-stanna-4-bora-cyclohexa-2,5-diene derivative (Wrackmeyer et al., 2013). The results of the X-ray structural analysis are shown in Figure 3. The six-membered ring is almost planar, with both tin and boron shifted slightly out of the plane formed by the four carbon atoms.

Figure 3. Molecular structure of a 1-stanna-bora-cyclohexa-2,5-diene derivative (hydrogen atoms have been omitted for clarity). On the right, the "twisted-boat" conformation of the central ring can be seen (Wrackmeyer et al., 2013). Selected bond lengths (pm) and angles ( $\left.{ }^{\circ}\right)$ : Sn1-C1 213.3(4), Sn1C17 214.6(4), C1-C2 135.2(6), C2-B1 156.2(7), B1-C22 160.8(6), C1-Sn1-C9 98.16(17), Sn1-C1-C2 120.4(4), Sn1-C9-C10 122.8(4), B1-C2-C1 126.5(4), B1-C10-C9 124.9(4), C2-B1-C10 127.0(4), C2-B1-C22 115.6(4), C10-B1-C22 117.3(4), C3-C2-B1 116.5 (4), C11-C10-B1 118.9(4), C3-C2-C1 117.0(4), C11-C10-C9 117.0(4)
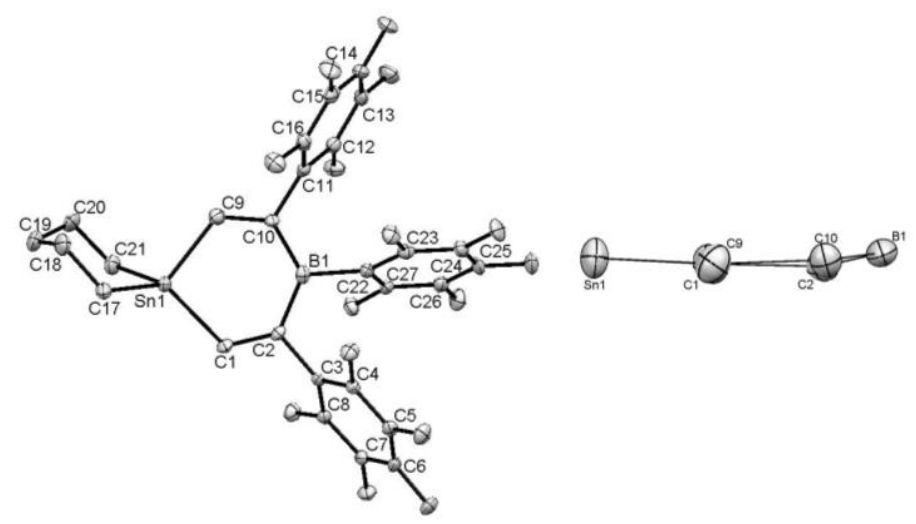

The whole situation becomes less predictable with substituents $\mathrm{R}^{1}$ other than $\mathrm{H}$ at the $\mathrm{C} \equiv \mathrm{C}$ bond. Thus, for $\mathrm{R}^{1}=\mathrm{Me}$, the 1,1-ethylboration does not give 
the stannole in appreciable quantity. Instead, the 1-stanna-4-bora-cyclohea-2,5diene (Scheme 5) was obtained along with a stannolene, and with triisopropylborane, $\mathrm{B}^{\mathrm{i}} \mathrm{Pr}_{3}$, the six-membered ring is formed selectively (Killian and Wrackmeyer 1978). With $\mathrm{R}^{1}={ }^{\mathrm{n}} \mathrm{Bu}$, again the six-membered ring is formed together with the stannole, whereas with $\mathrm{R}^{1}={ }^{\mathrm{t}} \mathrm{Bu}, \mathrm{Ph}$ only stannoles are formed. As for siloles (Scheme 4), reactions of bis(trimethylsilylethynyl)stannanes with many different triorganylboranes, $\mathrm{BR}_{3}$ $\left(\mathrm{R}=\right.$ alkyl, $\mathrm{Ph}$, and $\mathrm{C}_{6} \mathrm{~F}_{5}$ ) give exclusively stannoles (Wrackmeyer et al., 2003c; Wrackmeyer et al., 2014a).

Scheme 5. First attempts at the 1,1-organoboration of dialkynylstannanes gave selectively either stannoles or 1-stanna-4-bora-cyclohexa-2,5-dienes

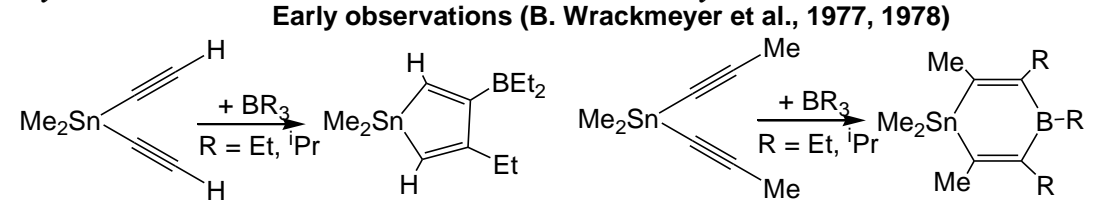

The search for intermediates to explain the formation of stannoles or 1stanna-4-bora-cyclohea-2,5-dienes started as early as 1977 and took several years until a zwitterionic lead derivative could be isolated at low temperature and characterised structurally (Wrackmeyer et al., 1989). Then, it proved possible to crystallise various zwitterionic tin derivatives (Figure 4), all supporting the mechanistic proposals (Wrackmeyer et al., 1993b; Wrackmeyer et al., 1994; Wrackmeyer et al., 2013; Wrackmeyer et al., 2014a). In all cases, the sum of bond angles at tin, counting the three $\sigma$-bonded substituents, approaches $360^{\circ}$, indicating the cationic character of the almost trigonal planar surrounded tin atoms, stabilised by side-on coordination to the respective $C \equiv C$ bond of an alkynylborate unit. The surroundings of the boron atoms are tetrahedral as in borates, and this is also confirmed by typical ${ }^{11} \mathrm{~B}$ NMR chemical shifts. 
Figure 4. Molecular structures of zwitterionic intermediates, which were isolated from the reactions of $\mathrm{Me}_{2} \mathrm{Sn}\left(\mathrm{C} \equiv \mathrm{C}_{-}{ }^{i} \mathrm{Pr}\right)_{2}$ with $\mathrm{BEt}_{3}$ (Wrackmeyer et al. 1993b) (A), $\mathrm{Me}_{2} \mathrm{Sn}\left(\mathrm{C} \equiv \mathrm{C}-\mathrm{CH}_{2} \mathrm{NMe}_{2}\right)_{2}$ with $\mathrm{BEt}_{3}$ (Wrackmeyer et al., 1994) (B), $\mathrm{CH}_{2}\left(\mathrm{CH}_{2}\right)_{4} \mathrm{Sn}(\mathrm{C} \equiv \mathrm{C} \text {-SiMe })_{2}$ with $\mathrm{B}\left(\mathrm{C}_{6} \mathrm{~F}_{5}\right)_{3}$ (Wrackmeyer et al., 2014a) $(\boldsymbol{C})$, and $\mathrm{CH}_{2}\left(\mathrm{CH}_{2}\right)_{4} \mathrm{Sn}(\mathrm{C} \equiv \mathrm{C}-\mathrm{H})_{2}$ with $\mathrm{B}\left(\mathrm{C}_{6} \mathrm{~F}_{5}\right)_{3}$ (Wrackmeyer et al., 2013 ) (D)
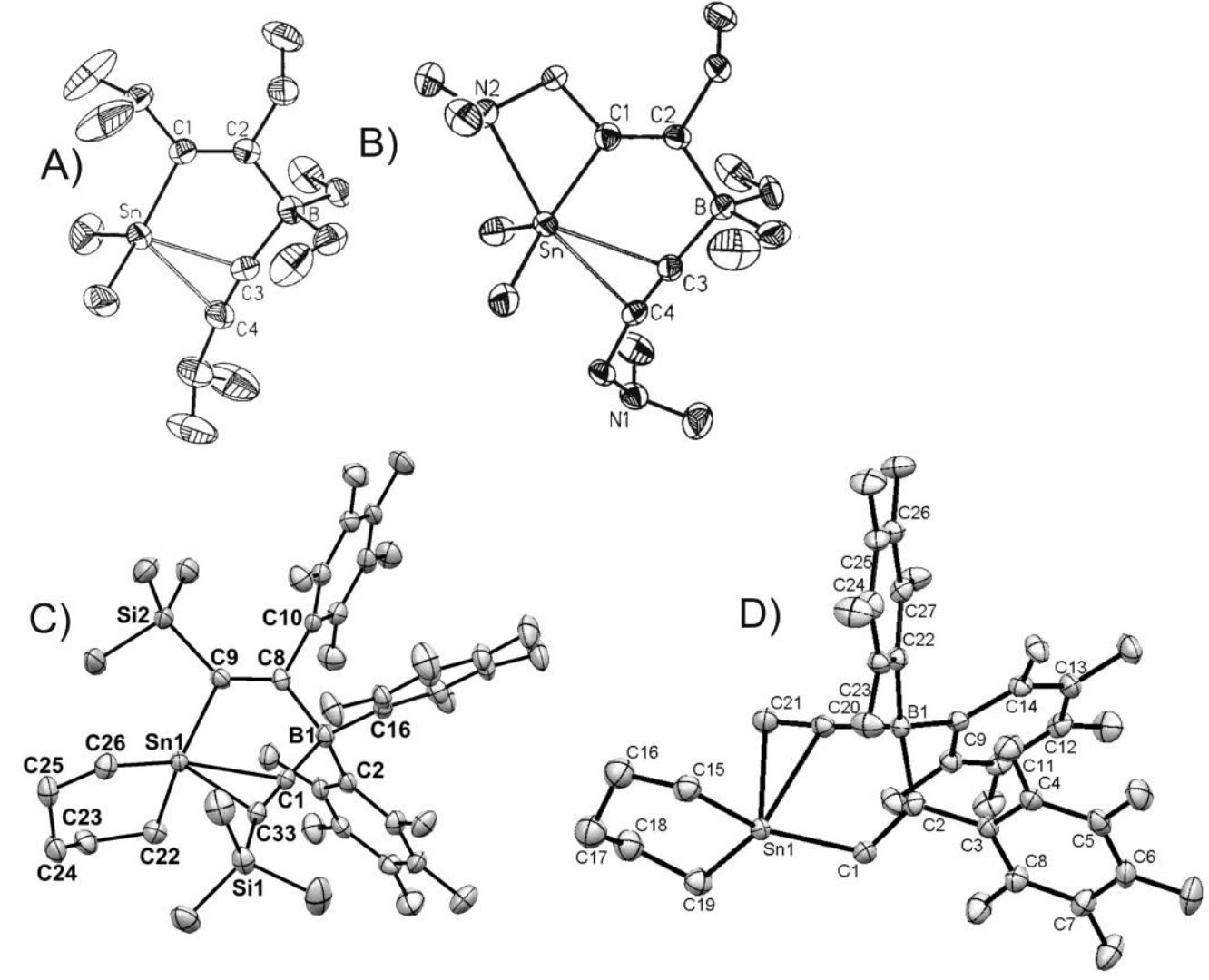

The direct structural evidence obtained so far and all consistent NMR spectroscopic data for both the solid state and solutions enable to propose a mechanism for the 1,1-carboboration of dialkynylmetal compounds, as outlined in Scheme 6. The reaction starts with inter-molecular activation of one of the $\mathrm{M}-\mathrm{C} \equiv$ bonds and 1,1-carboboration. Then, the second $\mathrm{M}-\mathrm{C} \equiv$ bond becomes activated, intra-molecularly, due to the favourable stereochemistry. The alkynyl group migrates from the metal to boron, leaving a cationic metal fragment and a borate unit in the zwitterionic intermediate. The final rearrangement affords either the metallole (1.1-vinylboration) or the 1-metalla4-bora-cyclohexa-2,5-diene (transfer of R). Kinetic and electronic effects, together with steric repulsion, decide which product is preferred. Fortunately, mixtures are rarely obtained, and both types of products are extremely attractive for further chemistry (e.g. Wrackmeyer et al., 1995b; Wrackmeyer and Klaus, 1996; Wrackmeyer et al., 2009). 
Scheme 6. Mechanism of the twofold 1,1-carboboration of dialkynylmetal compounds. The most important zwitterionic intermediate is highlighted

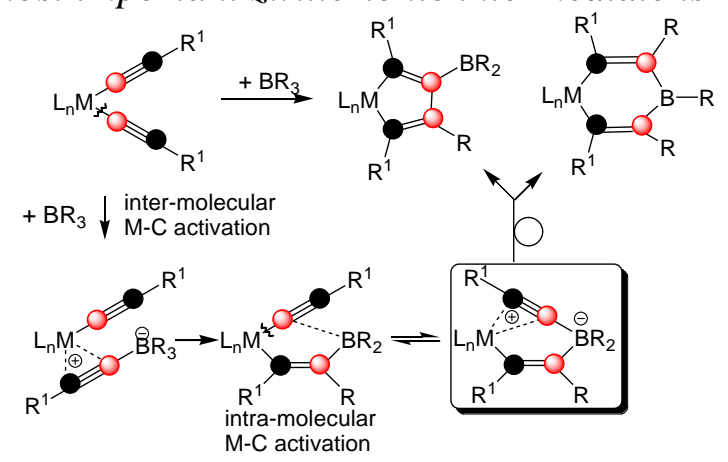

1,1-Organoboration of Tetraalkynylsilanes, -stannanes: 1,1'-Spirobisiloles, and 1,1'-Spirobistannoles

Following the protocol for the synthesis of siloles (Scheme 4), treatment of tetraalkynylsilanes with triethylborane in boiling toluene for prolonged periods of time gives 1,1 '-spirobisiloles, which can be readily protodeborylated, using acetic acid (Scheme 7).

Scheme 7. Fourfold 1,1-carboboration of tetra-1-propynylsilane, protodeborylation of the 1,1'-spirobislole and complexation with $\mathrm{Fe}(\mathrm{CO})_{3}$

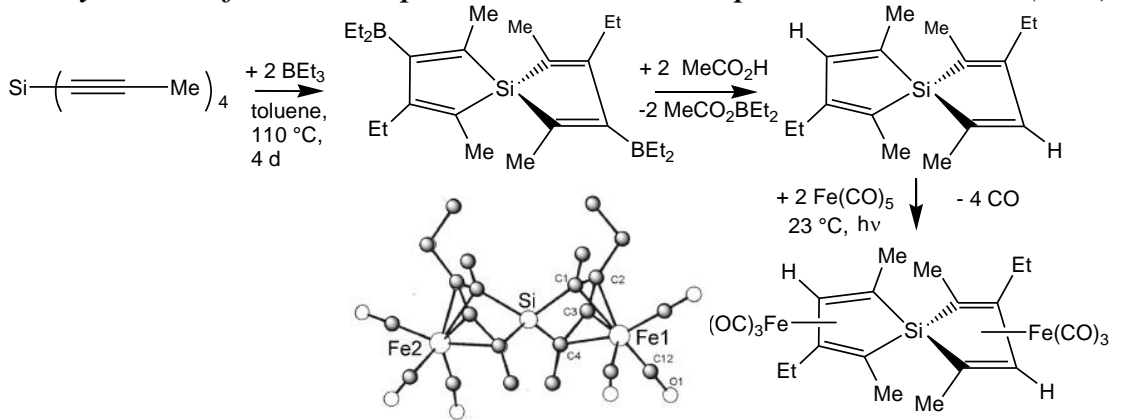

As shown above for the tetra-1-propynylsilane, the diene systems of the protodeborylated derivatives act as ligands towards $\mathrm{Fe}(\mathrm{CO})_{3}$ fragments, leading to a mixture of crystalline diastereomers, one of which could be purified and studied by X-ray crystallography (Köster et al., 1993b).

Since the stannanes are much more reactive than silanes, the stepwise 1,1organoboration of tetraalkynylstannanes can be easily monitored by NMR spectroscopic methods. In favourable cases, intermediates can be isolated prior to the formation of the final products, and the zwitterionic species, in which the tin atom bears formally two positive charges, is of particular interest (Wrackmeyer et al., 1991; Wrackmeyer et al., 1992a; Wrackmeyer, 1992b). 
Scheme 8. Stepwise 1,1-carboboration of tetraalkynylstannanes, leading to $1,1^{\prime}$-spirobistannoles.

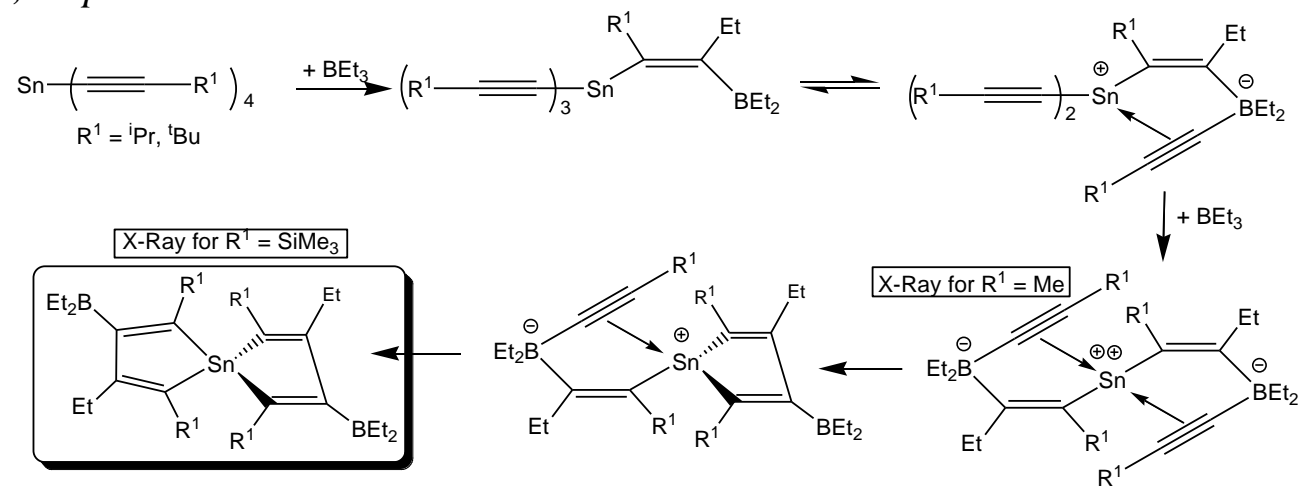

Combination of 1,2-Hydroboration with Intra-molecular 1,1-Organoboration of Alkynyl(vinyl)silanes

The harsh reaction conditions usually required to enforce inter-molecular 1,1-carboboration of alkynylsilanes hamper a more widespread application of this method. However, intra-molecular 1,1-carboboration may proceed much more smoothly. Therefore, the diorganoboryl group $\mathrm{BR}_{2}$ has to be introduced into the respective silane before 1,1-carboboration is taking place. This goal can be achieved by conventional well known 1,2-hydroboration (Brown, 1975), An $\mathrm{Si}-\mathrm{C} \equiv \mathrm{C}-\mathrm{R}^{1}$ function may already be present, waiting for the intra-molecular $\mathrm{Si}-\mathrm{C} \equiv$ activation, followed by 1,1-carboboration. The principles are shown in Scheme 9 for ethynyl(dimethyl)vinylsilane. The hydroborating reagent 9borabicyclo[3.3.1]nonane, 9-BBN, (Lane and Brown, 1971; Brown et al., 1974, Köster and Griaznov, 1961) reacts selectively with the vinyl group, placing the boryl unit at the terminal carbon atom (Brown, 1975). The stereochemistry is favourable for intra-molecular $\mathrm{Si}-\mathrm{C} \equiv$ bond activation, and 1,1-carboboration leads to the 1-silacyclopent-2-ene derivative (Wrackmeyer et al., 2014b) in agreement with theoretical calculations (Xia et al., 2008).

Scheme 9. Principles of combining 1,2-hydroboration and intra-molecular 1,1-carboboration (Wrackmeyer et al., 2005; Wrackmeyer et al., 2014b)

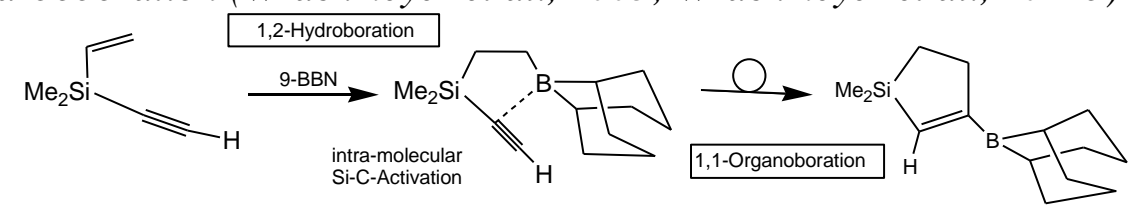

The vinyl group can be separated from $\mathrm{Si}$ by a $\mathrm{CH}_{2}$ or a $\mathrm{SiMe}_{2}$ unit, to give 1-silacyclohexenes or 1,2-disilacyclohexenes in the end. Moreover, the hydrogen atom of the ethynyl group can be replaced by many other substituents, including silyl groups. If an alkynylsilyl group is used, further intra-molecular 1,1-carboboration affords a silole derivative (Scheme 10) (Wrackmeyer et al., 2010, Wrackmeyer et al., 2014b). The ${ }^{13} \mathrm{C}$ NMR spectrum of such a silole is shown (Figure 5). The compound is obtained in essentially quantitative yield by the reaction of 9-BBN with 
$\mathrm{Me}_{2} \mathrm{Si}\left(\mathrm{CH}=\mathrm{CH}_{2}\right)-\mathrm{C} \equiv \mathrm{C}-\mathrm{SiMe}_{2}-\mathrm{C} \equiv \mathrm{C}-\mathrm{Ph}$. The typical broad and sharp ${ }^{13} \mathrm{C}$ NMR signals together with ${ }^{29} \mathrm{Si}$ satellites for coupling constants ${ }^{n} J\left({ }^{29} \mathrm{Si},{ }^{13} \mathrm{C}\right)$ serve for unambiguous structural assignment.

Scheme 10. Stepwise synthesis of a bicyclic silole, by combining 1,2hydroboration and twofold intra-molecular 1,1-carboboration

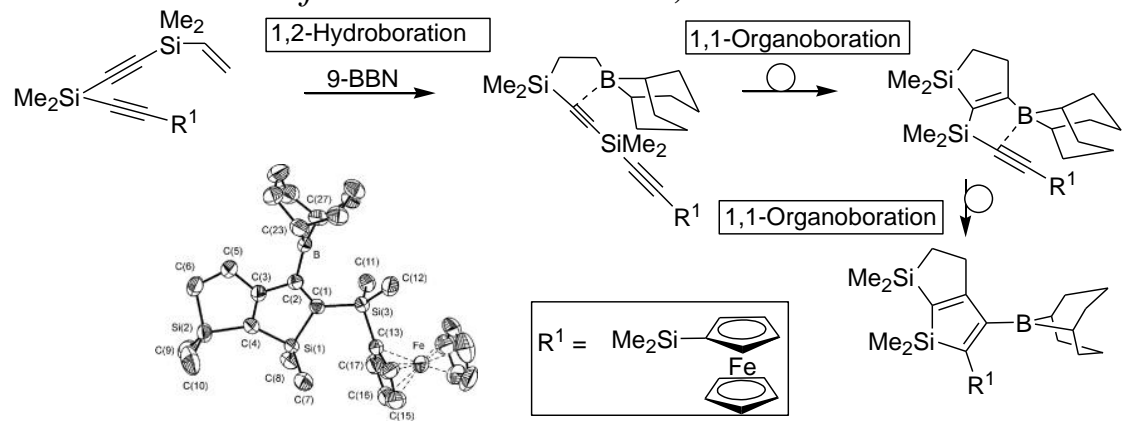

Figure 5. $\left.125.8 \mathrm{MHz}{ }^{13} \mathrm{C}^{1}{ }^{1} \mathrm{H}\right\} \mathrm{NMR}$ spectrum (in $\mathrm{C}_{6} \mathrm{D}_{6}$ at $296 \mathrm{~K}$ ) of a bicyclic silole derivative. Coupling constants ${ }^{n} \mathrm{~J}\left({ }^{29} \mathrm{Si},{ }^{13} \mathrm{C}\right)$ in $\mathrm{Hz}$ are given in brackets (Wrackmeyer et al., 2010)

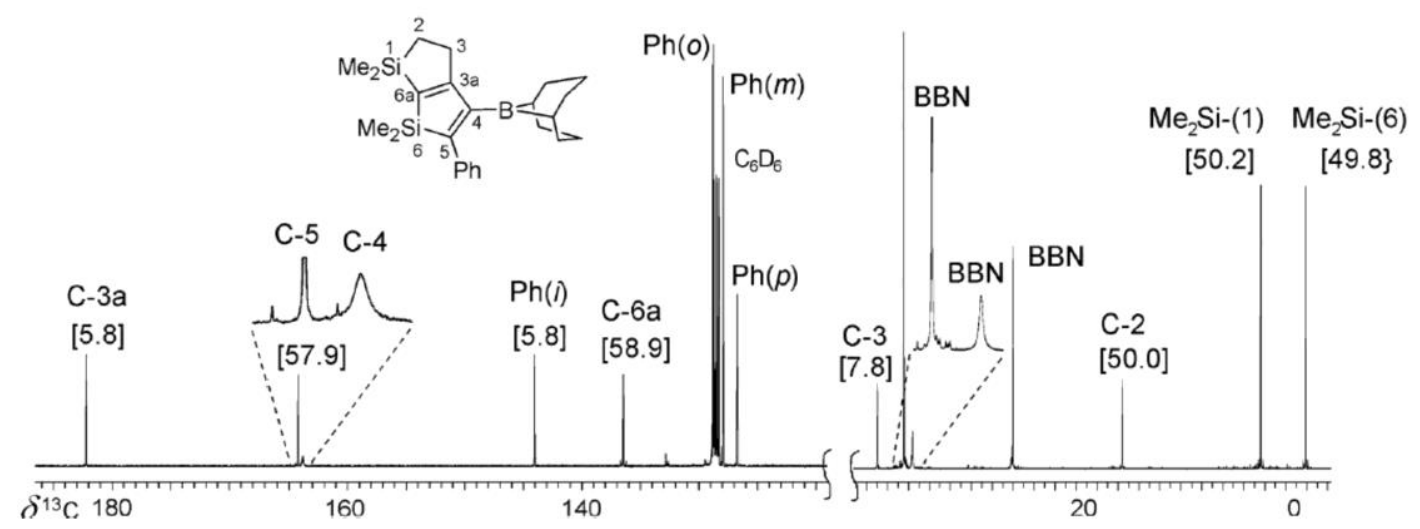

By increasing the number of $\mathrm{C} \equiv \mathrm{C}$ bonds, separated by $\mathrm{SiMe}_{2}$ units, the way opens to condensed siloles (Schemes 11, 12) (Wrackmeyer et al., 2010; Wrackmeyeret al., 2014b).

Scheme 11. Cascade-type sequence of 1,2-hydroboration and three 1,1carboborations of $\mathrm{Me}_{2} \mathrm{Si}\left(\mathrm{CH}=\mathrm{CH}_{2}\right)-\mathrm{C} \equiv \mathrm{C}-\mathrm{SiMe}_{2}-\mathrm{C} \equiv \mathrm{C}-\mathrm{SiMe}_{2}-\mathrm{C} \equiv \mathrm{C}-\mathrm{R}^{l}$ leads to condensed siloles (Wrackmeyer et al., 2010; Wrackmeyer et al., 2014b)
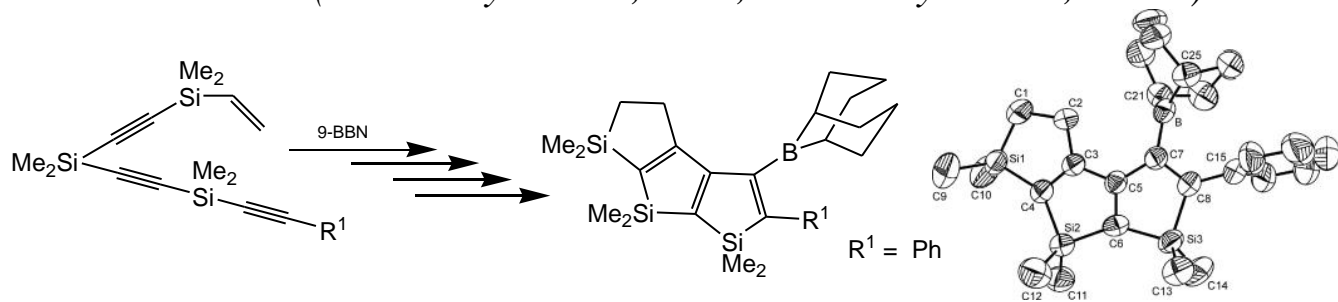
The molecular structure, shown in Scheme 11, reveals that all fivemembered rings are in one plane. This is no longer the case, when more fivemembered rings are fused. Thus, four fused rings (three of them siloles) already adopt a helical structure, both in the solid state (as shown) and in the solution (shown by non-equivalent methyl groups in ${ }^{1} \mathrm{H}$ and ${ }^{13} \mathrm{C}$ NMR spectra) of each of the $\mathrm{SiMe}_{2}$ units, in agreement with calculated optimised geometries [B3LYP/6-311+G(d,p)].

Figure 6. 99.4 MHz $\left.{ }^{29} \mathrm{Si}^{1}{ }^{1} \mathrm{H}\right\}$ NMR spectra (refocused INEPT; in $\mathrm{C}_{6} \mathrm{D}_{6}$ at 296 $K)$ of the reaction solutions containing the polycyclic compounds as shown (Tok et al., 2012). The assignment of the ${ }^{29}$ Si NMR signals in the upper trace is based on coupling constants $\left.{ }^{2} \mathrm{~J}^{29}{ }^{29} \mathrm{Si}^{29} \mathrm{Si}\right)$. All calculated [GIAO, B3LYP/6$311+G(d, p)] \delta^{29}$ Si data, in reasonable agreement with the experimental data, are given in parentheses

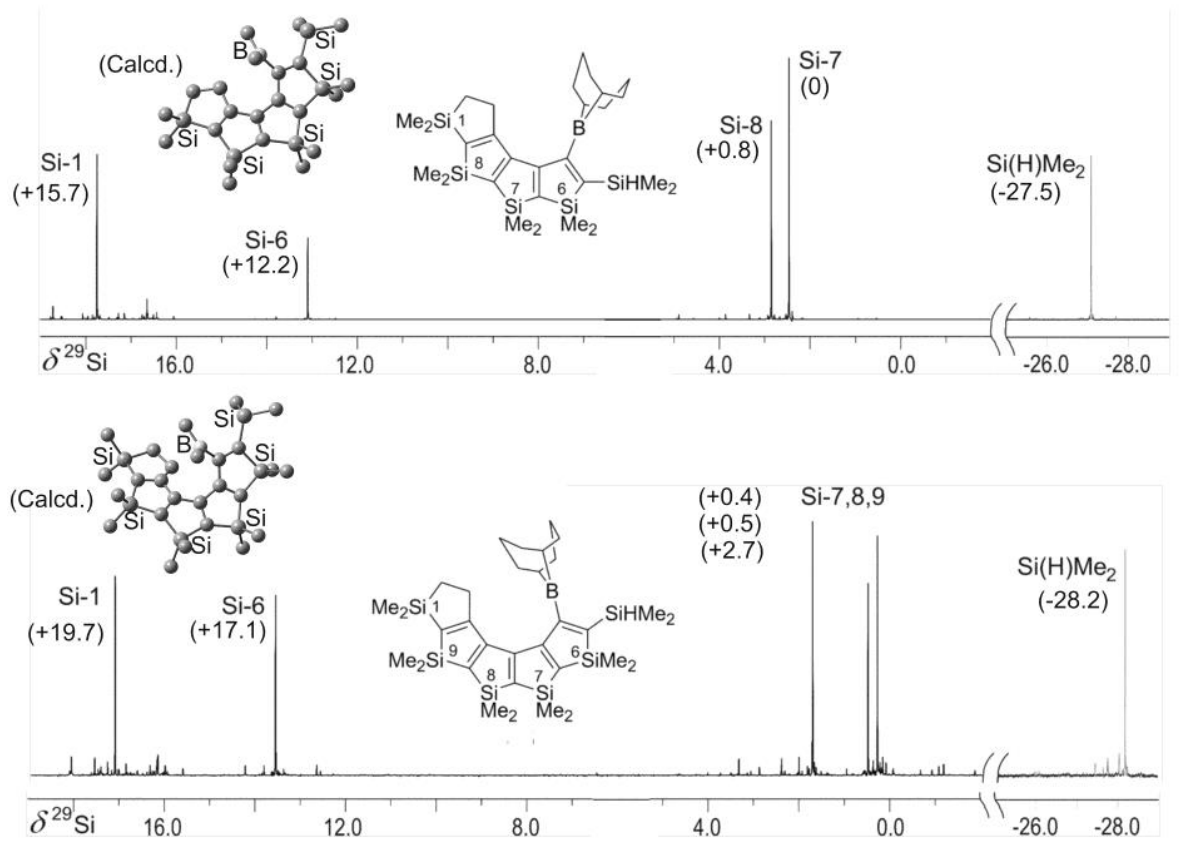

The monitoring of these multi-step reactions is important in order to isolate products of reasonable purity. For this purpose, ${ }^{29} \mathrm{Si}$ NMR spectroscopy is the method of choice (Figure 6), since the positions of ${ }^{29} \mathrm{Si}$ NMR signals for starting materials and intermediates differ significantly from those for the final products. 
Scheme 12. Cascade-type sequence of 1,2-hydroboration and four intramolecular 1,1-carboborations of $\mathrm{Me} e_{2} \mathrm{Si}\left(\mathrm{CH}=\mathrm{CH}_{2}\right)-\mathrm{C} \equiv \mathrm{C}$-SiMe $\mathrm{Si}_{2} \mathrm{C} \equiv \mathrm{C}$-SiMe $\mathrm{Si}_{2}$ $\mathrm{C} \equiv \mathrm{C}-\mathrm{SiMe}_{2}-\mathrm{C} \equiv \mathrm{C}-\mathrm{R}^{1}$ lead to tetracycles containing three condensed silole rings (Tok et al., 2012).
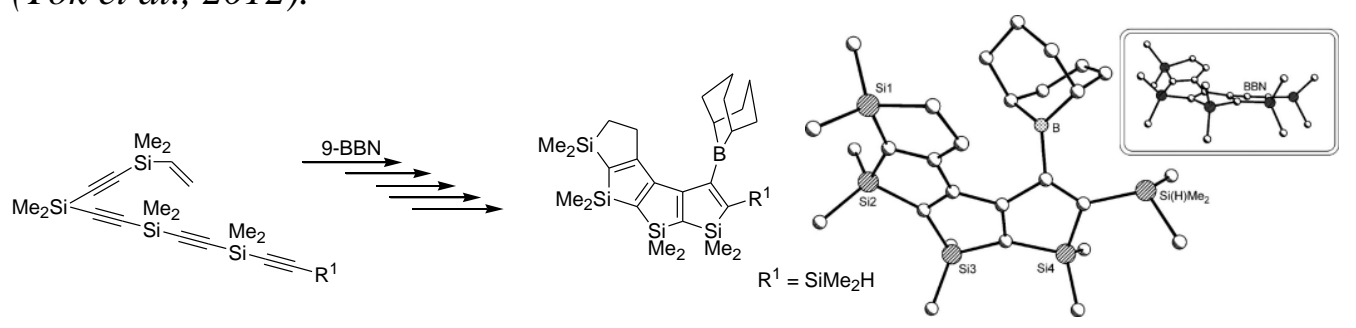

\section{Conclusions}

1,1-Carboboration of monoalkynylsilanes and -stannanes using triorganoboranes, $\mathrm{BR}_{3}$, proved to be a versatile method to obtain a large variety of organometallic-substituted alkenes. Dialkynylsilanes can be converted into siloles, whereas dialkynylstannaes afford either stannoles or 1-stanna-4-boracyclohexa-2,5-dienes, depending on substituents at boron and carbon. The mechanism of 1,1-carboboration has been firmly established by the isolation and structural characterization of zwitterionic intermediates. The extension of these 1,1-carboboration reactions towards tetralkynylsilanes and -stannanes gave 1,1'-spirobisiloles and 1,1'-spirobistannoles. Further progress has been made by developing the combination of 1,2-hydroboration and intra-molecular 1,1-carboboration. This reaction sequence introduces a diorganoboryl group into the respective silane under mild conditions, to initiate intra-molecular 1,1carboboration of an $\mathrm{Si}-\mathrm{C} \equiv \mathrm{C}-\mathrm{R}^{1}$ unit. Depending on the staring silanes, a huge variety of silaheterocyles became available, shown here by the synthesis of condensed polycyclic siloles, not available by any other known method. It was shown that multinuclear magnetic resonance methods $\left({ }^{1} \mathrm{H},{ }^{11} \mathrm{~B},{ }^{13} \mathrm{C},{ }^{29} \mathrm{Si}\right.$. and ${ }^{119} \mathrm{Sn}$ NMR spectroscopy) together with quantum-chemical analyses were perfectly suitable to assign the solution-state structures, which were found to be in agreement with results from X-ray structural analyses.

\section{Acknowledgments}

Support of this work by the Deutsche Forschungsgemeinschaft and Volkswagenstiftung is gratefully acknowledged.

\section{References}

Brandsma, L., 1988, Preparative Acetylenic Chemistry, $2^{\text {nd }}$ edition, Elsevier Oxford. Brown, H. C., Knights , E. F., and Scouten, C. G., 1974, Hydroboration. XXXVI. Direct Route to 9-Borabicyclo[3.3.1]nonane via the Cyclic Hydroboration of 1,5- 
Cyclooctadiene. 9-Borabicyclo[3.3.1]nonane as a Uniquely Selective Reagent for the Hydroboration of Olefins, J. Am. Chem. Soc., 96, 7765-7770.

Brown, H. C., 1975, Organic Syntheses via Boranes, Wiley. New York.

Davidsohn, W. E. and Henry, M. C., 1967, Organometallic Acetylenes of the Main Groups III-V, Chem. Rev. 67, 73.

Dierker, G., Ugolotti, J., Kehr, G., Fröhlich, R., and Erker, G., 2009, Reaction of bis(alkynyl)silanes with tris(pentafluorophenyl)borane: Synthesis of bulky silole derivatives by means of 1,1-carboboration under mild reaction conditions, Adv. Synth. Catal. 351, 1080-1088.

Hansmann, M. M. Melen, R. L.,Rominger, F., Hashmi, S. K., and Stephan, D. W., 2014, Activation of Alkynes with B(C6F5)3 - Boron Allylation Reagents Derived from Propargyl Esters, J. Amer. Chem. Soc. 136, 777-782.

Kehr, G. and Erker, G. 2012, 1,1-Carboboration, Chem. Commun. 48, 1839-1850.

Kehr, G.; Schwendemann, S.; and Erker, G., 2013, Intramolecular frustrated Lewis pairs: formation and chemical features, Topics Curr. Chem. 332, 45-84.

Khan, E., Wrackmeyer, B., and Kempe, R., 2008, Combination of 1,2-Hydroboration and 1,1-Organoboration. A Convenient Route to New 5-Silaspiro[4,4]nona-1,6diene Derivatives, Eur. J. Inorg. Chem. 5367-5372.

Khan, E., Bayer, S., and Wrackmeyer, B., 2009a, Syntheses of 1,1-Organo-substituted Silole Derivatives. 1,1-Ethylboration, 1,1-Vinylboration and Protodeborylation, Z. Naturforsch. Teil B, 64, 995-1002.

Khan, E., Kempe, R., and Wrackmeyer, B., 2009b, Synthesis and Molecular Structures of 1-Chloro-1-silacyclopent-2-enes, Combination of 1,2Hydroboration, 1,1-Organoboration and Protodeborylation, Appl. Organomet. Chem. 23, 124-131.

Khan, E., Bayer, S., Kempe, R., and Wrackmeyer, B., 2009c, Synthesis and Molecular Structure of Silole Derivatives Bearing Functional Groups on Silicon. 1,1Organoboration of Dialkyn-1-ylsilanes, Eur. J. Inorg. Chem. 4416-4424.

Khan, E. and Wrackmeyer, B., 2014, Synthesis of 1-Silacyclopent-2-ene Derivatives Using 1,2-Hydroboration, 1,1-Organoboration and Protodeborylation, Appl. Organomet. Chem. 28, 280-285.

Khan, E., Wrackmeyer, B., Döring, C., and Kempe, R., 2014, Synthesis and Characterization of Spirosilanes, 1,2-Hydroboration and 1,1-Carboboration, Eur. J. Inorg. Chem. 3411-3419.

Killian, L. and Wrackmeyer, B., 1977, Reaction of Triorganylboranes with dialkyl(diethynyl)stannanes, J. Organomet. Chem. 132, 213-221.

Killian, L. and Wrackmeyer, B., 1978, Reaction of Dialkyldi-1-propynylstannanes with Trialkylboranes, J. Organomet. Chem. 153, 153-164.

Köster, R. and Griaznov, 1961, Selektive Hydroborierung von Olefinen, Angew. Chem. 73, 171.

Köster, R. 1984, Organobor-Verbindungen, Houben-Weyl Methoden der Organischen Chemie, Vol. 13, 3, Thieme Stuttgart.

Köster, R., Seidel G., Wrackmeyer, B., Horchler, K., and Schlosser, D., 1989, Pentacoordinate Elements of Main Group 4 with four Organic Substituents, Angew. Chem. Int. Ed. Engl. 28, 918-919.

Köster, R., Seidel, G., Süß, J., and Wrackmeyer, B., 1993a, Organosubstitututed Siloles via twolfold Organoboration of Di-1-alkynylsilanews, Chem. Ber. 126, 1107-1114.

Köster, R., Seidel, G., Klopp, I., Krüger, C., Kehr, G., Süß, J., and Wrackmeyer, B., 1993b, Organosubstituted 1,1-Bisiloles and 1,1-Bigermoles via fourfold 
Organoboration of Tetra-1-alkynylsilanes and .germanes, Chem. Ber. 126, 13851396.

Lane, C, F. and Brown, H. C., 1971, Synthesis of secondary alkyl bromides in the reaction of bromine with B-secc-alkyl-9-borabicyclo[3.3.1]nonanes. Convenient procedure for the anti-Markovnikov hydrobromination of internal olefins, J. Organomet. Chem. 26, C51-C54.

Matteson, D. S., 1995, Stereodirected Synthesis with Organoboranes, Springer, Berlin, Heidelberg.

Pelter, A., Smith, K., and Brown, H. C., 1988, Borane Reagents, Academic Press, New York.

Piers, W. E. and Chivers, T. 1997, Pentafluorophenylboranes: from Obscurity to Applications, Chem. Soc. Rev. 26, 345-354.

Stephan, D. W., 2008, Frustrated Lewis pairs: a concept for new reactivity and catalysis. Org. Biomol. Chem. 6, 1535-1539.

Stephan, D. W. 2009, Frustrated Lewis pairs: a new strategy to small molecule activation and hydrogenation catalysis. Dalton Trans.38, 3129-3136.

Stephan, D. W. and Erker, G. 2010, Frustrated Lewis Pairs: Metal-free Hydrogen Activation and More, Angew. Chem., Int. Ed. 49, 46-76.

Stephan, D. and W., Erker, G. 2014, Frustrated Lewis pair chemistry of carbon, nitrogen and sulfur oxides. Chem. Sci, 6, 2625-2640.

Tok, O. L., Milius,W,, and Wrackmeyer, B., 2012, Synthesis and structure of fused siloles, npublished results, University of Bayreuth.

Ugolotti, J., Kehr, G,. Fröhlich, R; Erker, G: 2010, Photochemical isomerisation of boryl-substituted silole derivatives, Chem. Commun. 46, 3016-3018.

Wrackmeyer, B. and Zentgraf, R., 1978, Novel Synthesis of Substituted Allenes via Organoboration of Alkynylstannanes, J. Chem. Soc. Chem. Commun. 402.

Wrackmeyer, B. and Bihlmayer, C., 1981, Unexpected Products from the Reaction of Alkynylstannanes with 9-Bora-bicyclo[3.3.1]nonane, J. Chem. Soc. Chem. Commun. 1093.

Wrackmeyer, B., Bihlmayer, C., and Schilling, M., 1983, Alkene- und AlleneSynthesis, using reactive Boron-Carbon- and Boron-hydrogen Bonds, Chem. Ber. 116, 3182-3192.

Wrackmeyer, B., 1987, Organoboration of Metal Alkynes, Boron Chemistry Proceedings of the 6th International Meeting on Boron Chemistry (IMEBORON VI) (S. Heřmanek, ed.), World Scientific, Singapore. 387-415.

Wrackmeyer, B. and Wagner, K. 1989, A Convenient Route from Alkenylboranes to Alkenylstanmnanes, Chem. Ber. 122, 857-860.

Wrackmeyer, B., Horchler, K., Boese, R., 1989, Triorganolead Cations, stabilisest by side-on Coordination to the $\mathrm{C} \equiv \mathrm{C}$ Bond in Alkynylborates, Angew. Chem. Int. Ed. Engl. 28, 1500-1501.

Wrackmeyer, B. and Horchler, K., 1990, Dynamic Behavior and Rearrangements of Some Group 14 Organometallic Substituted Alkenylboranes, Organometallics 9, 1881-1886.

Wrackmeyer, B, and Wagner, K., 1991, Behaviour of cis-2-Boryl-1-stannyl-alkenen towards Dimethylamino-trimethylstannane, Methoxy-trimethylstannane and Methanol. Examples of Solvent-Controlled Reactions, Chem. Ber. 124, 503-508.

Wrackmeyer, B., Kehr, G., and Boese, R., 1991, $\pi$-Coordination to Diorganotin Dications. Angew. Chem. Int. Ed. Engl. 30, 1370-1372.

Wrackmeyer, B., Kehr, G., and Boese, R., 1992a, Organoboration of Tetrakis(trimethylsilylethinyl)stannane - X-Ray Structural Analysis of a 5Stannaspiro[4.4]nona-1,3,6,8-tetraene derivative, Chem. Ber. 125, 643-650. 
Wrackmeyer, B., Kehr, G., Sebald, A., and Kümmerlen, J., 1992b, Organotin Cations Stabilized by $\pi$ Coordination - Synthesis, Multinuclear Magnetic Resonance Studies $\left({ }^{1} \mathrm{H},{ }^{11} \mathrm{~B},{ }^{13} \mathrm{C},{ }^{119} \mathrm{Sn}\right)$ in Solution and ${ }^{13} \mathrm{C}$ and ${ }^{119} \mathrm{Sn} \mathrm{CP} / \mathrm{MAS}$ NMR in the Solid State, Chem. Ber. 125, 1597-1603.

Wrackmeyer, B., Wagner, K., and Boese, R., 1993a, Reactions of cis-Stannyl-borylalkenes with Sulfur Bis(trimethylsilylimide) and N-Sulfinyl(trimethylsilyl)amine - X-Ray Analysis of an 1-Amino-1 $\lambda^{4}$-thia-2-azonia-3-borata-1,4-cyclopentadiene, Chem. Ber. 126, 595-599.

Wrackmeyer, B., Kundler, S., and Boese, R., 1993b, Routes to Stannoles, Stannolenes and 1-Stanna-4-bora-2,5-cyclohexadienes - Crystal Structure of a Triorganotin Cation Stabilized by $\pi$-Coordination, Chem. Ber. 126, 1361-1370.

Wrackmeyer, B., Kehr, G., and Süß, J., 1993c, 1,1-Organoboration of Di-1alkynylsilanes with Alkynyl Groups of Different Reactivity: New Organometallic Substituted Siloles, Chem. Ber. 126, 2221-2226.

Wrackmeyer, B., Kundler, S., Milius, W., and Boese, R., 1994, Stabilization of Organotin Cations - Competition Between Coordinative O-Sn, S-Sn or N-Sn Bonds and Side-on $\pi$-Coordination to $\mathrm{C} \equiv \mathrm{C}$ Bonds, Chem. Ber. 127, 333-342.

Wrackmeyer, B., 1995a, 1,1-Organoboration of Alkynylsilicon,- Germanium,- Tin and -Lead Compounds, Coord. Chem. Rev. 145, 125-156.

Wrackmeyer, B., Klaus, U., and Milius, W., 1995b, Synthesis of 2- and 3-Stannolenes via Addition of Trimethyltin Alkoxides to 3-Diethylboryl-4-ethyl-1,1-dimethylstannole, Chem. Ber. 128, 679-687.

Wrackmeyer, B. and Klaus, U., 1996, New Phosphabenzenes by [4+2]Cycloaddition of Stannoles to 1-Phospha-1-alkynes - Determination of Signs of Coupling Constants $\left[{ }^{\mathrm{n}} \mathrm{J}\left({ }^{31} \mathrm{P},{ }^{13} \mathrm{C}\right),{ }^{\mathrm{n}} \mathrm{J}\left({ }^{31} \mathrm{P},{ }^{1} \mathrm{H}\right),{ }^{2} \mathrm{~J}\left({ }^{31} \mathrm{P},{ }^{29} \mathrm{Si}\right),{ }^{2} \mathrm{~J}\left({ }^{119} \mathrm{Sn},{ }^{31} \mathrm{P}\right)\right]$, J. Organomet. Chem. 520, 211-226.

Wrackmeyer, B., Dörfler, U., Kehr, G., Maisel, H. E., and Milius, W., 1996a, Organometallic-Substituted Allenes - Determination of Coupling Signs and Two Molecular Structures of Stannylated Allenes, J. Organomet. Chem. 524, 169-179.

Wrackmeyer, B., Klaus, U., and Milius, W., Klaus, E., Schaller, T., 1996b, Stannacyclohexanes and Spiro-Tin Compounds with a Stannole or a Stannolene Group, J. Organomet. Chem. 517, 235-242.

Wrackmeyer, B. and Süß, J., 2002, 1,1-Ethylboration of Diethynyl(dimethyl)silane: Formation of a Silole Followed by $[4+2]$ Cycloadditions to 7-Silanorbornadienes and 7-Silanorbornenes, Z. Naturforsch.Teil B, 57, 741-745.

Wrackmeyer, B., Maisel, H. E., Molla, E., Mottalib, A., Badshah, A., Bhatti, M. H., and Ali, S., 2003a, Combination of 1,2-Hydroboration and 1,1-Organoboration. Synthesis of Novel Organo-Substituted 1-Silacyclobutenes, Appl. Organomet. Chem. 17. 465-472.

Wrackmeyer, B., Tok, O. L., Bhatti, M. H., and Ali, S., 2003b, 1,1-Organoboration of Bis(trimethylstannyl)ethyne with Trimethylsilyl- and Dimethylsilyl-dialkylborylSubstituted Alkenes: Organometallic-Substituted Allenes, Appl. Organomet. Chem. 17, 843-850.

Wrackmeyer, B., Maisel, H. E., Milius, W., and Herberhold, M., 2003c, 1,3,2Diazastanna-[3]ferrocenophanes Bearing Alkyn-1-yl Groups at Tin and their 1,1Organoboration with Triethylborane - Molecular Structure of a Novel Spirotin Compound, J. Organomet. Chem. 680, 271-280.

Wrackmeyer, B., Tok, O. L., and Kempe, R., 2005, An Efficient Route to Substituted 1-Silacyclopent-2-enes and 1-Silacyclohex-2-enes via Consecutive 1,2Hydroboration and 1,1-Organoboration, Inorg. Chim. Acta 358, 4183-4190. 
Wrackmeyer, B., 2006, Metallacyclopentadienes and Related Heterocycles via 1,1Organoboration of Alkyn-1-ylmetal Compounds, Heteroatom Chem. 17, 188-206.

Wrackmeyer, B. and Tok, O. L., 2008, Comprehensive Heterocyclic Chemistry III, (Katritzky, A. R., Ramsden, C. A., Scriven, E. F. V., Taylor, J. J. K., eds.), Chapter 3.17, Elsevier, Oxford, 1181-1223.

Wrackmeyer, B., Tok, O. L., and Thoma, P., 2008a, 1,1-Ethylboration of Ethynyl(trimethyl)tin. (E)-1-Trimethylstannyl-2-diethylboryl-but-1-ene, Isomerization and Conversion into Hydridoborates, ARKIVOC 6-18.

Wrackmeyer, B., Khan, E., and Kempe, R., 2008b, Synthesis and Structure of Novel Spirosilanes. Combination of 1,2-Hydroboration and 1,1-Organoboration, Appl. Organomet. Chem. 22, 383-388.

Wrackmeyer, B., Thoma, P., and Kempe, R., 2009, Stannoles Bearing a Diethylboryl Group in 3-Position: Reactions with Isocyanates, Eur. J. Inorg. Chem. 14691476.

Wrackmeyer, B., Tok, O. L., Klimkina, E. V., and Milius, W., 2010, Fused Silacarbacycles Containing a Silole Unit. 1,2-Hydroboration and 1,1Organoboration of Alkynyl(vinyl)silanes, Eur. J. Inorg. Chem. 2276-2282.

Wrackmeyer, B., Thoma, P., Marx, S., Glatz, G., and Kempe, R., 2013, 1,1Carboboration of Dialkynyltin Compounds Using Triorganoboranes of Greatly Different Lewis Acid Strength. 1,4-Stannabora-cyclohexa-2,5-dienes and Characterization of Zwitterionic Intermediates, Z. Anorg. Allg. Chem. 639, 12051213.

Wrackmeyer, B., Thoma, P., Marx, S., Bauer, T., and Kempe, R., 2014a, Selective Synthesis of Stannoles via 1,1-Carboboration of Bis(trimethylsilylethynyl)tin Compounds Using Weakly and Strongly Electrophilic Triorganoboranes. Characterization of a Zwitterionic Intermediate, Eur. J. Inorg. Chem. 2103-2112.

Wrackmeyer, B., Klimkina, E. V., Milius, W., Butterhof, C., and Inzenhofer, K., 2014b, 1,2-Hydroboration and 1,1-Carboboration of Alkynyl(ferrocenyl)vinylsilanes. Novel Siloles, Z. Naturforsch. Teil B, 12691289.

Xia, Y., Li, Y., and Li, W., 2008, Theoretical Study on the Consecutive 1,2Hydroboration and 1,1-Organoboration Reactions of Alkyn-1-yl(vinyl)silane with borane, J. Organomet. Chem. 693, 2722-2728.

Yamamoto, H., 1999, Lewis acid reagents: a practical approach. Oxford University Press, New York. 